\title{
Adropin in women with polycystic ovary syndrome
}

\author{
Justyna Kuliczkowska-Płaksej', Agata Mierzwicka ${ }^{1}$, Maja Jończyk ${ }^{1}$, Barbara Stachowska' \\ Alina Urbanovych ${ }^{2}$, Marek Bolanowski ${ }^{1}$
}

${ }^{1}$ Department of Endocrinology, Diabetes, and Isotope Therapy, Wroclaw Medical University, Poland, Wroclaw, Poland

${ }^{2}$ Endocrinology Department of Danylo Halytsky Lviv National Medical University, Ukraine

\begin{abstract}
Introduction: Women with polycystic ovary syndrome (PCOS) frequently develop metabolic complications. Among the newly found factors responsible for metabolic disorders, adropin seems to be of a great significance.

Material and methods: In total 134 women aged 17-45 years were enrolled. The PCOS group consisted of 73 women, diagnosed on the basis of Executive Committee of the European Society of Human Reproduction and Embryology - American Society for Reproductive Medicine (ESHRE-ASRM) criteria. All PCOS women presented phenotype A of PCOS. The control group consisted of 61 women with regular menstrual cycles, matched for nutritional status. All women underwent anamnesis, physical examination, anthropometric measurements, abdominal and transvaginal ultrasound, and dual-energy X-ray absorptiometry (DXA). Serum adropin levels were determined by ELISA. Biochemical [fasting glucose and insulin, oral glucose tolerance test, lipid and sex hormone-binding globulin (SHBG)] and hormonal (testosterone, androstenedione, luteinizing hormone, follicle-stimulating hormone and oestradiol) measurements were performed. Insulin resistance indices [(Homeostasis Model Assessment for Insulin Resistance (HOMA-IR), Quantitative Insulin Sensitivity Check Index (QUICKI), Matsuda] and free androgen index (FAI) were calculated according to the standard formula.

Results: Serum adropin levels were lower in the PCOS group $(0.475 \pm 0.200$ vs. $0.541 \pm 0.220, \mathrm{p}=0.069)$, but the results were not statistically significant. Positive correlations among adropin and androstenedione levels were observed in the PCOS group $(r=0.27, p=0.025)$. Conclusions: Women with PCOS have a different metabolic profile in comparison to women without this syndrome. We did not observe a statistically significant difference in adropin concentration between the PCOS and the healthy control group. Therefore, more studies regarding adropin in PCOS are needed. (Endokrynol Pol 2019; 70 (2): 151-156)
\end{abstract}

Key words: adropin; polycystic ovary syndrome; metabolic syndrome

\section{Introduction}

Polycystic ovary syndrome (PCOS) is the most common endocrinopathy in the group of reproductive-aged women, with a prevalence of $6-25 \%$, depending on the diagnostic criteria used [1]. This is a complex syndrome consisting of menstrual disorders, hyperandrogenism and ovarian dysfunction. Although metabolic disorders are not included in the diagnostic criteria, they are an integral part of this syndrome [2]. The number of studies on new peptides crucial in the pathogenesis of metabolic disorders is rapidly increasing. Among the new potential factors responsible for metabolic disorders, adropin seems to be of a great significance.

Adropin is a 76-amino acid peptide hormone (4499.9 $\mathrm{Da}$ ) coded by the energy homeostasis associated gene (Enho). It was first isolated in 2008 by Kumar et al. from hepatic cells [3]. Animal model studies showed that Enho gene expression was regulated by nutrition, but the exact mechanism of the action was not fully understood. Mice fed on a high-fat and low-carbohydrate diet had rapid increase in Enho gene expression and higher adropin serum levels. On the other hand, animals fed on low-fat and high-carbohydrate diet presented lower adropin serum levels [4]. Additionally, mice with knock-out adropin gene developed fat growth, insulin resistance (IR), and dyslipidaemia. Furthermore, adropin administered parenterally reduced food intake, leading to weight loss in obese mice [4]. In another animal study on rats with diet-induced obesity (DIO) and IR, Gio et al. showed that adropin administration to DIO mice enhanced glucose tolerance, ameliorated IR, and promoted preferential use of carbohydrate over fat in fuel selection [5]. Based on these reports, it has been concluded that adropin could play an important role in maintaining energy homeostasis and regulating lipid metabolism, thus preventing dyslipidaemia, IR, and impaired glucose tolerance (IGT) [3-6].

Human studies in gestational diabetes, type 2 diabetes mellitus (DM 2), and nonalcoholic fatty liver disease (NAFLD) patients noted decreased plasma adropin levels [7-9]. The results of research in obese adults showed that adropin levels were also lower in these individuals [10]. On the other hand, the results 
of studies of obese children are contradictory [11, 12]. Decreased plasma adropin levels were also observed in patients with acute myocardial infarction (AMI) and coronary atherosclerosis [8, 13].

There are four reports available on adropin in women with PCOS. The authors concluded that the serum adropin levels were lower in the PCOS group in all of them [14-17]. One study showed a negative correlation between adropin and fasting insulin levels, Homeostasis Model Assessment for Insulin Resistance (HOMA-IR), total cholesterol, very-low-density lipoprotein cholesterol (VLDL), and triglycerides (TG) [14]. On the other hand, Kume et al. demonstrated that adropin levels were negatively correlated with fasting insulin and glucose levels, HOMA-IR, body mass index (BMI), total cholesterol, low-density lipoprotein cholesterol (LDL), and TG. In this study the relations between adropin and tumour necrosis factor alpha (the level of which was higher in PCOS) was also examined. However, no correlation between these two parameters was found [15]. Intal and Sen also demonstrated lower adropin in a PCOS group $[16,17]$.

The aims of our study were to assess serum adropin levels in PCOS patients in comparison to women without menstrual disturbances, matched for nutritional status (BMI), and to assess correlations between adropin serum levels and metabolic and hormonal markers.

\section{Material and methods}

\section{Patients}

A total of 134 women aged $17-45$ years were enrolled. The PCOS group consisted of 73 women hospitalised in the Department of Endocrinology, Diabetes, and Isotope Therapy in Wroclaw. All PCOS women fulfilled three Rotterdam criteria, including biochemical hyperandrogenism. Exclusion criteria included all other endocrinopathies associated with hyperandrogenism. The nonPCOS group consisted of sixty-one women with regular menstrual cycles, recruited among the students and patients with simple obesity without hormonal disorders. Both groups were matched for nutritional status.

\section{Methods}

PCOS was diagnosed on the basis of Executive Committee of the European Society of Human Reproduction and Embryology - American Society for Reproductive Medicine (ESHRE-ASRM) criteria (Rotterdam criteria), including three of the following: oligoor anovulation, biochemical hyperandrogenism, and polycystic ovaries on ultrasound $[18,19]$. All patients underwent anamnesis and physical examination as well as transvaginal and abdominal ultrasound. Anthropometric measurements (weight, height, waist and hip circumferences) were performed in all women. BMI was calculated as the ratio of weight $(\mathrm{kg})$ to height squared $\left(\mathrm{m}^{2}\right)$. Waist-to-hip ratio (WHR) was calculated as the ratio of waist circumference $(\mathrm{cm})$ to hip circumference $(\mathrm{cm})$. Android (abdominal) obesity was diagnosed when WHR was greater than or equal to 0.8 . Abdominal ultrasound examination was performed in all subjects to assess the hepatosteatosis. Body composition (android and gynoid distribution) was measured with dual-energy X-ray absorptiometry (DXA).
To conduct biochemical analyses, venous blood samples $(15 \mathrm{ml})$ were collected from the women in the follicular phase of menstrual cycle in the morning following an overnight fast. Hormonal and biochemical analyses were performed, then plasma was collected and frozen at $-70^{\circ} \mathrm{C}$ until further assayed.

Serum adropin level was determined by ELISA (Peninsula Laboratories International, San Carlos, California, USA) using a BioTek EL 800 analyser.

Biochemical measurements: fasting glucose and insulin, two-hour blood glucose and insulin level after glucose overload (2-h OGTT), lipid and sex hormone-binding globulin (SHBG) levels and hormonal measurements: total testosterone (T), androstenedione, luteinising hormone ( $\mathrm{LH})$, follicle-stimulating hormone (FSH), and oestradiol levels were also performed. IR indices (HOMA, Quantitative Insulin Sensitivity Check Index [QUICKI], Matsuda) were calculated according to the standard formulas. The free androgen index (FAI) was calculated as the ratio of the total testosterone level to SHBG level multiplied by 100.

\section{Statistics analysis}

EPIINFO Ver. 7.1.1.14 was used for statistical analysis. Distribution of parameters was determined using Kolmogorov-Smirnov test. For all groups, expected values (x), medians (M), range from minimum to maximum (min-max), standard deviations (SD), and lower and upper quartiles (25Q-75Q) were measured. Verification of equation of mean parameters in independent groups was performed by Student t-test in case of parametric and Mann Whitney U-test in nonparametric distribution. In tables, depending on the distribution of variables, the parameters are expressed as the mean \pm standard deviation (normal distribution) or as the median and the lower and upper quartile (distribution deviated from the normal). For selected pairs of parameters, linear regression analysis was performed by calculating Pearson's correlation coefficient.

\section{Results}

\section{Anthropometric parameters}

Anthropological characteristics of the groups are presented in Table I. PCOS patients were older than non-PCOS. There were no significant differences in $\mathrm{BMI}$ between groups. Statistically significant differences $(0.836 \pm 0.097$ vs. $0.802 \pm 0.087, \mathrm{p}<0.05)$ in waist-to-hip ratio (WHR) and android distribution of fat $(32.4 \pm 10$ vs. $27.1 \pm 9.2, \mathrm{p}<0.05)$ were observed, while there were no statistically significant differences in waist circumference and total body fat between groups.

\section{Metabolic results}

Biochemical and hormonal characteristics of the patients are given in Table II. Subjects with PCOS had lower HDL cholesterol levels (55.1 \pm 20.6 vs. $67 \pm 20.8, \mathrm{p}<0.05)$ and higher TG levels (119 \pm 65.3 vs. $77.8 \pm 37.8, \mathrm{p}<0.001)$. There were no statistically significant differences in total cholesterol and LDL cholesterol levels between groups. PCOS women had higher fasting (9.15 \pm 7.08 vs. $6.11 \pm 6.21, \mathrm{p}<0.05)$ and 2-h OGTT $(71.8 \pm 62.1$ vs. $38.1 \pm 23.7, \mathrm{p}<0.001)$ serum insulin levels. There were no statistically significant differences in fasting and 2-h OGTT glucose levels. Statistically significant differences in IR indices were observed - HOMA-IR was higher $(1.94 \pm 1.56$ vs. $1.23 \pm 1.51, \mathrm{p}<0.001)$, QUICKI 
Table I. Anthropological characteristics of the groups

\begin{tabular}{|c|c|c|c|}
\hline & PCOS patients $(n=73)$ & Non-PCOS patients $(\mathrm{n}=61$ ) & $\mathbf{p}$ \\
\hline Age [years] & $\begin{array}{c}24.3 \pm 4.823 .0 \\
(20.0-27.0)\end{array}$ & $\begin{array}{c}29.2 \pm 6.4 \\
28.0(23.0-34.0)\end{array}$ & $<0.001$ \\
\hline Weight [kg] & $\begin{array}{c}76.2 \pm 19.0 \\
75.0(61.0-89.0)\end{array}$ & $\begin{array}{c}69.6 \pm 13.3 \\
65.0(60.0-77.0)\end{array}$ & $0.034^{*}$ \\
\hline $\mathrm{BMI}\left[\mathrm{kg} / \mathrm{m}^{2}\right]$ & $\begin{array}{c}27.5 \pm 6.4 \\
26.4(22.3-31.6)\end{array}$ & $\begin{array}{c}25.3 \pm 4.7 \\
24.2(22.5-26.6)\end{array}$ & $0.078^{*}$ \\
\hline Waist circumference [cm] & $\begin{array}{c}88.7 \pm 16.9 \\
84.0(75.5-101.5)\end{array}$ & $\begin{array}{c}84.5 \pm 12.4 \\
80,0(76.0-92.0)\end{array}$ & $0.208^{*}$ \\
\hline WHR & $\begin{array}{c}0.836 \pm 0.097 \\
0.829(0.763-0.896)\end{array}$ & $\begin{array}{c}0.802 \pm 0.087 \\
0.793(0.750-0.857)\end{array}$ & $0.036^{*}$ \\
\hline Body fat (\%) & $\begin{array}{c}34.8 \pm 6.8 \\
35.1(30.9-40.0)\end{array}$ & $\begin{array}{c}33.1 \pm 6.5 \\
33.3(27.8-38.2)\end{array}$ & $0.143^{\#}$ \\
\hline Android fat distribution (\%) & $\begin{array}{c}32.4 \pm 10.0 \\
33.2(25.2-40.7)\end{array}$ & $\begin{array}{c}27.1 \pm 9.2 \\
25.8(19.4-33.7)\end{array}$ & $0.002^{\#}$ \\
\hline Gynoid fat distribution (\%) & $\begin{array}{c}37.8 \pm 5.9 \\
37.7(34.6-41.3)\end{array}$ & $\begin{array}{c}37.2 \pm 5.8 \\
37.1(33.1-41.8)\end{array}$ & $0.596^{\#}$ \\
\hline
\end{tabular}

PCOS — polycystic ovary syndrome; BMI — body mass index; WHR — waist-to-hip ratio; $\mathrm{p}$ — statistical significance; * — difference between medians,

$\#$ - difference between mean \pm SD

Table II. Metabolic and hormonal characteristics of the groups

\begin{tabular}{|c|c|c|c|}
\hline & PCOS patients $(n=73)$ & Non-PCOS patients $(n=61)$ & $\mathbf{p}$ \\
\hline $\mathrm{TC}[\mathrm{mg} / \mathrm{dL}]$ & $\begin{array}{c}191.3 \pm 35.5 \\
192.0(165.5-210.0)\end{array}$ & $\begin{array}{c}180.2 \pm 38.5 \\
179.0(160.0-202.0)\end{array}$ & $0.090^{\#}$ \\
\hline LDL-C [mg/dL] & $\begin{array}{c}112.3 \pm 33.7 \\
111.5(85.0-128.5)\end{array}$ & $\begin{array}{c}106.6 \pm 35.5 \\
106.5(83.0-129.0)\end{array}$ & $0.341^{\#}$ \\
\hline $\mathrm{HDL}-\mathrm{C}[\mathrm{mg} / \mathrm{dL}]$ & $\begin{array}{c}55.1 \pm 20.6 \\
52.0(40.5-65.0)\end{array}$ & $\begin{array}{c}67.0 \pm 20.8 \\
65.0(48.0-84.5)\end{array}$ & $0.001^{\#}$ \\
\hline $\mathrm{TG}[\mathrm{mg} / \mathrm{dL}]$ & $\begin{array}{c}119.0 \pm 65.3 \\
96.5(70.5-154.5)\end{array}$ & $\begin{array}{c}77.8 \pm 37.8 \\
675(51.5-94.5)\end{array}$ & $<0.001 *$ \\
\hline $\mathrm{FBG}[\mathrm{mg} / \mathrm{dL}]$ & $\begin{array}{c}84.4 \pm 6.9 \\
86.0(79.0-89.0)\end{array}$ & $\begin{array}{c}79.4 \pm 20.0 \\
82.0(76.0-90.0)\end{array}$ & $0.244^{*}$ \\
\hline $2 \mathrm{~h}$ OGTT $[\mathrm{mg} / \mathrm{dL}]$ & $\begin{array}{c}100.0 \pm 26.5 \\
95.0(86.0-112.0)\end{array}$ & $\begin{array}{c}91.5 \pm 25.5 \\
87.0(74.0-107.0)\end{array}$ & $0.067^{\#}$ \\
\hline Flns $[\mu \mathrm{lU} / \mathrm{mL}]$ & $\begin{array}{c}9.15 \pm 7.08 \\
7.08(2.80-14.30)\end{array}$ & $\begin{array}{c}6.11 \pm 6.21 \\
4.91(2.00-7.01)\end{array}$ & $0.007^{*}$ \\
\hline $2 \mathrm{~h} \operatorname{lns}[\mu \mathrm{IU} / \mathrm{mL}]$ & $\begin{array}{c}71.8 \pm 62.1 \\
49.5(30.0-93.9)\end{array}$ & $\begin{array}{c}38.1 \pm 23.7 \\
33.1(23.6-50.1)\end{array}$ & $0.001 *$ \\
\hline HOMA-IR & $\begin{array}{c}1.94 \pm 1.56 \\
1.31(0.55-3.02)\end{array}$ & $\begin{array}{c}1.23 \pm 1.51 \\
0.80(0.40-1.36)\end{array}$ & $0.001 *$ \\
\hline QUICKI & $\begin{array}{c}0.372 \pm 0.054 \\
0.367(0.324-0.426)\end{array}$ & $\begin{array}{c}0.397 \pm 0.052 \\
0.384(0.365-0.449)\end{array}$ & $0.008^{\#}$ \\
\hline Matsuda index & $\begin{array}{c}7.89 \pm 6.08 \\
5.39(3.41-11.36)\end{array}$ & $\begin{array}{c}11.9 \pm 6.8 \\
10.8(6.7-17.3)\end{array}$ & $0.001^{\#}$ \\
\hline Total T [ng/mL] & $\begin{array}{c}0.750 \pm 0.325 \\
0.680(0.520-0.920)\end{array}$ & $\begin{array}{c}0.356 \pm 0.133 \\
0.330(0.240-0.440)\end{array}$ & $<0.001 *$ \\
\hline SHBG [nmol/L] & $\begin{array}{c}33.4 \pm 21.6 \\
27.0(18.3-38.0)\end{array}$ & $\begin{array}{c}59.6 \pm 30.8 \\
54.3(36.8-75.1) \\
\end{array}$ & $<0.001 *$ \\
\hline FAl (\%) & $\begin{array}{c}9.36 \pm 4.00 \\
8.70(6.83-11.22)\end{array}$ & $\begin{array}{c}2.54 \pm 1.43 \\
2.17(1.49-3.21)\end{array}$ & $<0.001 *$ \\
\hline Androstenedione [ng/mL] & $\begin{array}{c}5.72 \pm 2.24 \\
4.97(4.35-7.37)\end{array}$ & $\begin{array}{c}2.63 \pm 1.02 \\
2.56(1.82-3.30)\end{array}$ & $<0.001 *$ \\
\hline
\end{tabular}


Table II. Metabolic and hormonal characteristics of the groups

\begin{tabular}{|c|c|c|c|}
\hline & PCOS patients $(n=73)$ & Non-PCOS patients $(n=61$ ) & $\mathbf{p}$ \\
\hline $\mathrm{LH}[\mathrm{mlU} / \mathrm{mL}]$ & $\begin{array}{c}11.7 \pm 5.9 \\
10.3(7.5-14.6)\end{array}$ & $\begin{array}{c}5.95 \pm 3.16 \\
5.16(4.00-6.91)\end{array}$ & $<0.001 *$ \\
\hline $\mathrm{FSH}[\mathrm{mlU} / \mathrm{mL}]$ & $\begin{array}{c}5.78 \pm 1.45 \\
5.94(5.14-6.83)\end{array}$ & $\begin{array}{c}5.99 \pm 2.37 \\
5.79(4.41-8.08)\end{array}$ & $0.766 *$ \\
\hline LH/FSH & $\begin{array}{c}2.06 \pm 1.04 \\
1.89(1.26-2.65)\end{array}$ & $\begin{array}{c}1.31 \pm 1.33 \\
0.93(0.68-1.34)\end{array}$ & $<0.001^{\#}$ \\
\hline $\mathrm{E} 2[\mathrm{pg} / \mathrm{mL}]$ & $\begin{array}{c}64.7 \pm 45.0 \\
53.9(44.5-67.8)\end{array}$ & $\begin{array}{c}98.3 \pm 95.3 \\
71.1(28.2-117.0)\end{array}$ & $0.262^{\#}$ \\
\hline Steatohepatitis & $\begin{array}{l}\text { Yes }-44 \text { patients } \\
\text { No }-29 \text { patients }\end{array}$ & $\begin{array}{l}\text { Yes }-27 \text { patients } \\
\text { No }-34 \text { patients }\end{array}$ & $0.064^{\#}$ \\
\hline AIAT & $\begin{array}{c}22.7 \pm 8.5 \\
20.0(17.0-26.5)\end{array}$ & $\begin{array}{c}19.5 \pm 7.4 \\
19.0(15.0-22.0)\end{array}$ & $0.028^{\#}$ \\
\hline AspAT & $\begin{array}{c}23.9 \pm 13.4 \\
18.5(14.0-31.5)\end{array}$ & $\begin{array}{c}18.7 \pm 10.2 \\
16.0(13.0-20.0)\end{array}$ & $0.025 *$ \\
\hline
\end{tabular}

PCOS - polycystic ovary syndrome; TC - total cholesterol, LDL-C — low-density lipoprotein cholesterol; HDL-C — high-density lipoprotein cholesterol; TG - triglyceride; FBG — fasting blood glucose; $2 \mathrm{~h}$ OGTT — $2 \mathrm{~h}$ blood glucose after glucose overload; Flns — fasting insulin; $2 \mathrm{~h}$ Ins — 2-h blood insulin after glucose overload, HOMA-IR — homeostatic model assessment-insulin resistance index; QUICKI — quantitative insulin sensitivity check index; T — testosterone; SHBG — sex hormone binding globulin; FAI — free androgen index; LH — luteinising hormone; LH/FSH — luteinising hormone-to-follicle stimulating hormone ratio; E2 — oestradiol; AIAT — alanine aminotransferase; AspAT — aspartate aminotransferase; $p$ — statistical significance; ${ }^{*}$ — difference between medians; \# — difference between mean \pm SD

Table III. Serum adropin levels in groups

\begin{tabular}{lcc}
\hline & PCOS patients $(\mathbf{n}=73)$ & Non-PCoS patients $(\mathbf{n}=\mathbf{6 1})$ \\
\hline Adropin $[\mathrm{ng} / \mathrm{ml}]$ & $0.475 \pm 0.200$ & $0.541 \pm 0.220$ \\
& $0.447(0.370-0.542)$ & $0.487(0.424-0.595)$ \\
\hline
\end{tabular}

PCOS — polycystic ovary syndrome; $p$ - statistical significance; ${ }^{*}$ — difference between medians

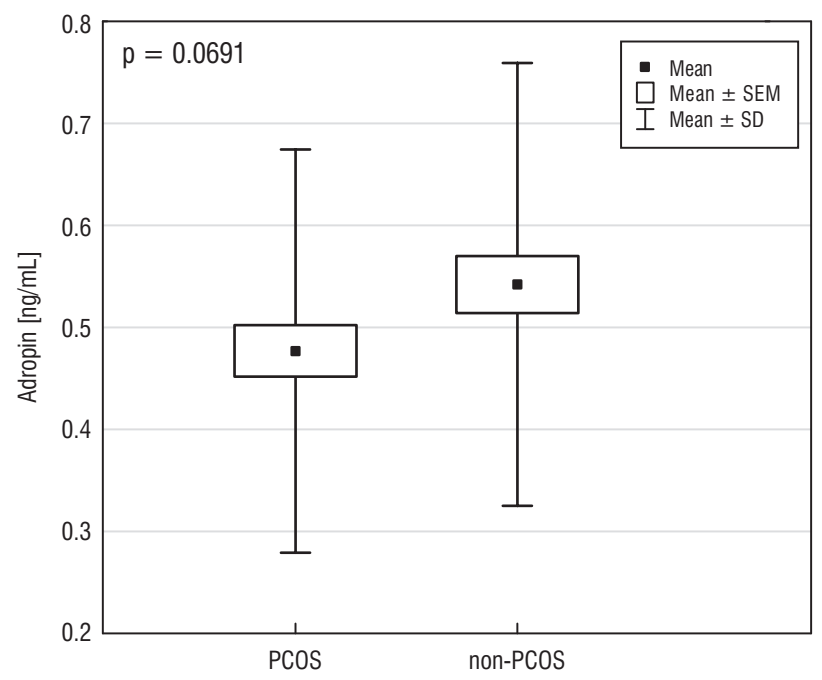

Figure 1. Serum adropin levels in patients with polycystic ovary syndrome (PCOS) and without PCOS (non-PCOS). $p$ - statistical significance; SEM — standard error of the mean; SD - standard deviation

$(0.372 \pm 0.054$ vs. $0.397 \pm 0.052, \mathrm{p}<0.05)$ and Matsuda index $(7.89 \pm 6.08$ vs. $11.9 \pm 6.8, \mathrm{p}<0.001)$ were lower in PCOS women. Also noted were significantly higher total testosterone $(0.75 \pm 0.325$ vs. $0.356 \pm 0.133$, $\mathrm{p}<0.001)$, androstenedione ( $5.72 \pm 2.24$ vs. $2.63 \pm 1.02$, $\mathrm{p}<0.001)$, and FAI levels $(9.36 \pm 4$ vs. $2.54 \pm 1.43$, $\mathrm{p}<0.001)$ in PCOS patients. Women with PCOS had a higher prevalence of hepatic steatosis, but this result was not statistically significant. Alanine and aspartate transaminase (AlAT and AspAT) levels were statistically significantly higher $(22.7 \pm 8.5$ vs. $19.5 \pm 7.4$ and $23.9 \pm 13.4$ vs. $18.7 \pm 10.2$, respectively, $\mathrm{p}<0.05)$ in PCOS women.

Serum adropin levels were lower in PCOS group (Tab. III, Fig. 1) but this result was not statistically significant $(0.475 \pm 0.2$ vs. $0.541 \pm 0.22, p=0.0691)$. In addition, the positive correlation among adropin and AlAT $(\mathrm{r}=0.236, \mathrm{p}=0.046)$ as well as adropin and androstenedione $(r=0.27, p=0.025)$ levels were observed in the PCOS group. However, no other significant correlations between adropin levels and metabolic and hormonal markers were observed.

\section{Discussion}

Among the new factors responsible for metabolic disorders, adropin seems to be of great significance. 
PCOS is typically associated with metabolic complications; therefore, it might be possible that the levels of peptides involved in the aetiopathogenesis of metabolic disorders might be changed in women with PCOS [20, 21].

In our study serum adropin levels were lower in PCOS patients, but this result was not statistically significant ( $p=0.069)$, which is probably due to the small sample size. In four available studies on adropin in PCOS women, Kume, Yildrim, Inal, and Sen presented significantly lower adropin concentrations in women with PCOS compared to a control group. In all of these studies, serum adropin level was negatively correlated with IR indices [14-17].

The results of our study did not show the correlations between adropin levels and fasting and 2-h glucose and insulin levels. There was also no correlation with IR indices, including HOMA-IR.

Studies on animals have suggested a possible adropin effect on the carbohydrate metabolism. Kumar, in his first study on animals, showed that mice with the knock-out gene of adropin presented impaired glucose tolerance (IGT), which could suggest the role of adropin in the development of IR and DM2 [4]. In another study, Aydin demonstrated higher amounts of adropin in pancreas, liver, brain, cerebellum, and kidneys of rats with diabetes induced by streptozotocin (STZ) [22]. However, Akciar et al., in recent study in rats with STZ-induced diabetes, showed that the adropin levels were significantly lower in those with diabetes. They demonstrated that the adropin administration caused a significant decrease of fasting glucose level, HOMA-IR, and $\mathrm{HbA}_{1}$. The authors suggested that adropin could improve glucose metabolism and insulin sensitivity by inhibition the production of inflammatory cytokines [23].

$\mathrm{Wu}$ et al. confirmed the observation that patients with DM2 had significantly lower adropin levels [8]. The results of the studies on pregnant women with GDM were consistently showing lower serum adropin levels in this group $[8,24,25]$. However, Beigi et al. did not show any correlations between adropin and fasting glucose levels in GDM women [24]. Similarly, Lian et al. did not find these correlations in patients with heart insufficiency [26]. On the other hand, Butler et al. demonstrated a negative correlation between adropin and fasting glucose levels in obese patients [10]. A similar correlation was found by Kume in PCOS patients [15]. Kume and Yildrim showed also negative correlations between adropin and HOMA-IR and fasting insulin levels in PCOS patients [14, 15].

Thus, the results of recent studies are contradictory. In our study, women in both groups did not have elevated glucose levels. Therefore, it could be a reason for the lack of correlation. Further studies are needed to determine the impact of adropin on glucose and insulin metabolism.

There was no correlation between serum adropin levels and lipids in our studies. No correlation was also found in Lian's study of patients with heart insufficiency [26] and Beigi's report in GDM women [24].

The animal studies suggested that adropin had an impact on fat metabolism. Akciar et al. demonstrated that adropin administered parenterally reduced the total cholesterol, TG, and LDL cholesterol levels and increased HDL cholesterol levels in mice with DM [23]. Butler, in his study in obese patients, reported that serum adropin levels were negatively correlated with TG and LDL cholesterol levels and positively correlated with HDL cholesterol and FFA levels [10]. Kume et al. also demonstrated negative correlation between adropin and total cholesterol, LDL cholesterol, and TG in PCOS patients [15]. Similar correlations were found by Butler et al. in obese patients. They also showed a positive correlation between adropin and HDL cholesterol [10]. Yildrim showed a negative correlation between adropin and total cholesterol, TG, and VLDL cholesterol in PCOS women [14].

The results of recent studies are not always consistent. However, they show that adropin has some effects on lipid metabolism, but further studies are needed to clarify the issue.

In the present analysis, we found correlation between serum adropin levels and androstenedione, but not with testosterone. There were few findings showing correlations between adropin and androgens. Kume did not find any correlation between adropin and androgens [15]. Therefore, it seems to be worthwhile to expand our study.

In the present research, we found that serum adropin levels were correlated neither with BMI nor with any other anthropometric parameters. These results were confirmed in other studies $[9,24,25]$. On the other hand, Lian et al. showed that the serum adropin levels were positively correlated with BMI in patients with heart insufficiency [26]. However, most studies showed a negative correlation between adropin and BMI [10, 12-14]. Butler et al. also demonstrated that the adropin serum levels were negatively correlated with BMI in obese patients. Moreover, they observed that the adropin levels increased after Roux-en-Y gastric bypass, peaking three months after surgery [10].

Moreover, it was shown that adropin levels were dependent on dietary preferences in female patients. The serum adropin levels were positively correlated with fat intake and negatively correlated with carbohydrate intake in women [27]. Animal studies conducted by Kumar confirmed these observations [4]. 
Based on these studies, it seems that adropin plays a role in energy homeostasis and possibly protects against obesity and IR by regulating fat and carbohydrate metabolism.

The limitations of this study need to be considered. Firstly, our groups were not in the same age range. PCOS women were younger, hence metabolic disorders might not have been advanced enough. A major limitation is also the small sample size; according to power analysis, the power of our test was $60 \%$ (sample size calculation - 157 patients in one group). The IR indices (HOMA-IR, QUICKI, Matsuda) were used to diagnose IR. The "gold standard" is the euglycemic metabolic clamp; however, this test is difficult to perform in outpatients, so we resigned from this method. It is also worth considering the determination of adropin after glucose loading and observing its variable postprandial concentrations. The strength of our study is that our PCOS group was homogenous according to PCOS criteria - all PCOS patients were hyperandrogenic (phenotype A).

\section{Conclusions}

Serum adropin levels were lower in the PCOS group, but this result was not statistically significant. In addition, a positive correlation between adropin and androstenedione levels was observed in the PCOS group. However, no other significant correlations between adropin levels and metabolic and hormonal markers were observed. Adropin seems to be a protective factor against IR and DIO. It would be valuable to conduct further studies to assess the impact on, and relation of, adropin with metabolic disorders typically associated with PCOS.

\section{Disclosure statement}

The authors declare they have no conflict of interest.

\section{Funding}

This study was supported by Grant no. STM.C120.16.013 of Wroclaw Medical University.

\section{References}

1. Setji TL, Brown AJ. Polycystic ovary syndrome: update on diagnosis and treatment. Am J Med. 2014; 127(10): 912-919, doi: 10.1016/j.amjmed.2014.04.017, indexed in Pubmed: 24859638

2. Pasquali R, Gambineri A. New perspectives on the definition and management of polycystic ovary syndrome. J Endocrinol Invest. 2018; 41(10): 1123-1135, doi: 10.1007/s40618-018-0832-1, indexed in Pubmed: 29363047.

3. Kumar KG, Trevaskis JL, Lam DD, et al. Identification of adropin as a secreted factor linking dietary macronutrient intake with energy homeostasis and lipid metabolism. Cell Metab. 2008; 8(6): 468-481, doi: 10.1016/j.cmet.2008.10.011, indexed in Pubmed: 19041763.

4. Ganesh Kumar K, Zhang J, Gao Su. Adropin deficiency is associated with increased adiposity and insulin resistance. Obesity (Silver Spring). 2012; 20(7): 1394-1402, doi: 10.1038/oby.2012.31, indexed in Pubmed: 22318315.

5. Gao Su, McMillan RP, Zhu Q, et al. Therapeutic effects of adropin on glucose tolerance and substrate utilization in diet-induced obese mice with insulin resistance. Mol Metab. 2015; 4(4): 310-324, doi: 10.1016/j. molmet.2015.01.005, indexed in Pubmed: 25830094.
6. Mierzwicka A, Bolanowski M. Nowe peptydy odgrywające rolę w zaburzeniach metabolicznych. Post Hig Med Dosw. 2016; 70: 881-886.

7. Celik E, Yilmaz E, Celik O, et al. Maternal and fetal adropin levels in gestational diabetes mellitus. J Perinat Med. 2013; 41(4): 375-380, doi: 10.1515/jpm-2012-0227, indexed in Pubmed: 23314506.

8. Wu L, Fang J, Chen L, et al. Low serum adropin is associated with coronary atherosclerosis in type 2 diabetic and non-diabetic patients. Clin Chem Lab Med. 2014; 52(5): 751-758, doi: 10.1515/cclm-2013-0844, indexed in Pubmed: 24323892.

9. Sayın O, Tokgöz Y, Arslan N. Investigation of adropin and leptin levels in pediatric obesity-related nonalcoholic fatty liver disease. J Pediatr Endocrinol Metab. 2014; 27(5-6): 479-484, doi: 10.1515/jpem-2013-0296, indexed in Pubmed: 24468600.

10. Butler AA, Tam CS, Stanhope KL, et al. Low circulating adropin concentrations with obesity and aging correlate with risk factors for metabolic disease and increase after gastric bypass surgery in humans. J Clin Endocrinol Metab. 2012; 97(10): 3783-3791, doi: 10.1210/jc.2012-2194, indexed in Pubmed: 22872690.

11. Kocaoglu C, Buyukinan M, Erdem SS, et al. Are obesity and metabolic syndrome associated with plasma adropin levels in children? J Pediatr Endocrinol Metab. 2015; 28(11-12): 1293-1297, doi: 10.1515/jpem-2015-0117, indexed in Pubmed: 26226125.

12. Altincik A, Sayin O. Evaluation of the relationship between serum adropin levels and blood pressure in obese children. J Pediatr Endocrinol Metab. 2015; 28(9-10): 1095-1100, doi: 10.1515/jpem-2015-0051, indexed in Pubmed: 26030787

13. Yu Hy, Zhao P, Wu Mc, et al. Serum adropin levels are decreased in patients with acute myocardial infarction. Regul Pept. 2014; 190-191: 46-49, doi: 10.1016/j.regpep.2014.04.001, indexed in Pubmed: 24731968.

14. Yildirim B, Celik O, Aydin S. Adropin: a key component and potential gatekeeper of metabolic disturbances in policystic ovarian syndrome. Clin Exp Obstet Gynecol. 2014; 41(3): 310-312, indexed in Pubmed: 24992783

15. Kume T, Calan M, Yilmaz O, et al. A possible connection between tumor necrosis factor alpha and adropin levels in polycystic ovary syndrome. J Endocrinol Invest. 2016; 39(7): 747-754, doi: 10.1007/s40618-016-0453-5, indexed in Pubmed: 26969461.

16. Inal ZO, Erdem S, Gederet $Y$, et al. The impact of serum adropin and ischemia modified albumin levels based on BMI in PCOS. Endokrynol Pol. 2018; 69(2): 135-141, doi: 10.5603/EP.a2018.0002, indexed in Pubmed: 29465156.

17. Sen H, Erbag G, Bınnetoglu E, et al. Adropin levels in polycystic ovary syndrome patients. J Clin Anal Med. 2017; 8(1), doi: 10.4328/jcam.4508.

18. Fauser BC, Tarlatzis BC, Rebar RW, et al. Consensus on women's health aspects of polycystic ovary syndrome (PCOS): the Amsterdam ESHRE/ASRM-Sponsored 3rd PCOS Consensus Workshop Group. Fertil Steril. 2012; 97(1): 28-38.e25, doi: 10.1016/j.fertnstert.2011.09.024, indexed in Pubmed: 22153789.

19. Rotterdam ESHRE/ASRM-Sponsored PCOS Consensus Workshop Group. Revised 2003 consensus on diagnostic criteria and long-term health risks related to polycystic ovary syndrome (PCOS). Hum Reprod. 2004; 19(1): 41-47, indexed in Pubmed: 14688154.

20. Apridonidze S, Essah PA, Iuorno MJ. Prevalence and characteristics of the metabolic syndrome in women with polycystic ovary syndrome. J Clin Endocrinol Metab. 2005; 90(4): 1929-1935, doi: 10.1210/jc.2004-1045, indexed in Pubmed: 15623819

21. Behboudi-Gandevani S, Amiri M, Bidhendi Yarandi R, et al. The risk of metabolic syndrome in polycystic ovary syndrome: A systematic review and meta-analysis. Clin Endocrinol (Oxf). 2018; 88(2): 169-184, doi: 10.1111/cen.13477, indexed in Pubmed: 28930378.

22. Aydin S, Kuloglu T, Aydin S, et al. Expression of adropin in rat brain, cerebellum, kidneys, heart, liver, and pancreas in streptozotocin-induced diabetes. Mol Cell Biochem. 2013; 380(1-2): 73-81, doi: 10.1007/s11010-013-1660-4, indexed in Pubmed: 23620340.

23. Akcilar R, Kocak FE, Simsek H, et al. Antidiabetic and hypolipidemic effects of adropinin streoptozotocin-induced type 2 diabetic rats. Bratis Lek Listy. 2016; 117(2): 100-105, indexed in Pubmed: 26830041.

24. Beigi A, Shirzad N, Nikpour F, et al. Association between serum adropin levels and gestational diabetes mellitus; a case-control study. Gynecol Endocrinol. 2015; 31(12): 939-941, doi: 10.3109/09513590.2015.1081681, indexed in Pubmed: 26376846.

25. Aydin S, Kuloglu T, Aydin S. Copeptin, adropin and irisin concentrations in breast milk and plasma of healthy women and those with gestational diabetes mellitus. Peptides. 2013; 47: 66-70, doi: 10.1016/j. peptides.2013.07.001, indexed in Pubmed: 23850897.

26. Lian W, Gu X, Qin Y, et al. Elevated plasma levels of adropin in heart failure patients. Intern Med. 2011; 50(15): 1523-1527, indexed in Pubmed: 21804276.

27. St-Onge MP, Shechter A, Shlisky J, et al. Fasting plasma adropin concentrations correlate with fat consumption in human females. Obesity (Silver Spring). 2014; 22(4): 1056-1063, doi: 10.1002/oby.20631, indexed in Pubmed: 24115373. 